\title{
Accumulation phenomena in fluvial processes and the corresponding stochastic model
}

\author{
JING Huan ${ }^{1},{ }^{*}$ ZHONG Deyu ${ }^{1,2}$, ZHANG Hongwu ${ }^{1}$, SHI Xufang ${ }^{3}$, WANG Yanjun ${ }^{1}$ \\ 1. State Key Laboratory of Hydroscience and Engineering, Tsinghua University, Beijing 100084, China; \\ 2. State Key Laboratory of Plateau Ecology and Agriculture, Qinghai University, Xining 810016, China; \\ 3. School of Water Resources and Electric Power, Qinghai University, Xining 810016, China
}

\begin{abstract}
Accumulation occurs widely in fluvial processes. Accurately accounting for the effects of previous water and sediment conditions on accumulation is essential for studying riverbed evolution. In this study, to reveal the physical mechanisms of accumulation, various geometric observations of both the upstream and downstream reaches of dams on several typical fluvial channels were analyzed. The changes in water and sediment conditions were defined as external disturbances. Assuming that the probability of an external disturbance conforms to a Poisson distribution, and that the response intensity induced by an individual disturbance decays exponentially over time, a mathematical description of the accumulation of internal responses to external disturbances is given. Furthermore, a corresponding theoretical model for simulating the spatiotemporal readjustments of characteristic river variables is proposed based on stochastic theory. The proposed models are then applied to investigate spatiotemporal readjustment in the upper and lower reaches of dams following their construction. The results indicate that temporally, the vertical, lateral, and overall readjustment rates of the reaches are relatively fast in the early period following dam construction but then decrease rapidly over time. Accumulated riverbed degradation, channel width, and sedimentation continuously increase until a new dynamic equilibrium is reached. These phenomena reflect the representative accumulation characteristics of fluvial processes. Spatially, the erosion intensities in downstream reaches decrease nonlinearly along the channel until eventually diminishing. The unbalanced spatial distribution of erosion intensity arises from the system response characterized by propagation in space but decay over time, which is characteristic of accumulation phenomena after disturbances. The results of the developed model show that the spatiotemporal readjustments of the studied cross-sections and channel reaches can be accurately described by the unified theoretical formula derived herein. The model predictions show good agreement with observed field data with determination coefficients of $0.92,0.93,0.76$, and 0.95 for vertical, lateral, longitudinal, and overall readjustments, respectively. The proposed theoretical models account for both the accumulation characteristics of fluvial processes and their spatial distributions. In demonstrating the proposed ap-
\end{abstract}

Received: 2019-12-03 Accepted: 2020-02-08

Foundation: National Natural Science Foundation of China, No.91547204; National Key Research and Development Program of China, No.2016YFC0402500, No.2017YFC0404303

Author: Jing Huan (1993-), PhD Candidate, specialized in river mechanics. E-mail: jingh16@mails.tsinghua.edu.cn

*Corresponding author: Zhong Deyu (1970-), Professor, specialized in basic theory of sediment movement.

E-mail: zhongdy@mail.tsinghua.edu.cn 
proach, this study provides a theoretical basis and new calculation method for quantitatively describing the spatiotemporal readjustments of non-equilibrium fluvial channels following external disturbances.

Keywords: accumulation phenomenon; fluvial process; accumulated riverbed degradation; channel width; accumulated erosion and sedimentation

\section{Introduction}

In nature, physical processes with different spatial and temporal scales are the results of accumulated internal and/or external effects. Accumulation phenomena are commonly observed in various natural processes, including fluvial systems. Generally, in a fluvial system, the runoff and sediment from the basin are the basic inputs of material and energy, and their accumulation is the fundamental driving force of all kinds of fluvial processes. For instance, as a flow carrying sediment enters a wide river valley or estuary, the dramatic widening of the water surface causes a sharp decrease in flow velocity and substantial sediment deposition, which eventually contributes to the formation of alluvium and an estuarine delta. This pattern explains the formation of the North China Plain in the lower Yellow River and the Yangtze Delta adjacent to the East China Sea (Xie, 2013). Consequently, in terms of material and energy, the formations of fluvial deposits can be regarded as the result of the long-term accumulation of sediment carried by currents. In fluvial systems, all changes in the water and sediment conditions can be seen as external disturbances to which the fluvial systems respond immediately. The internal responses to external disturbances gradually accumulate in the system, altering the path of river evolution by adjusting the channel geometry until the new channel geometry is suitable for the incoming flow and sediment regime. It follows that the morphologies of rivers are related not only to the current flow and sediment conditions, but also to all previous events during a certain historical period. In this paper, the characteristics of fluvial processes are called "accumulation characteristics", and the quantity used to describe the accumulated effects on fluvial systems is called "accumulation action". Accumulation action can be used to quantitatively measure the effects of historical disturbances on riverbed evolution.

In the past few decades, the accumulation effects of previous water and sediment conditions have attracted considerable attention. Qian et al. (1972) investigated reservoir sedimentation in a sediment-laden river and found that bankfull discharge was closely related to the average annual discharge during flood seasons, indicating that the current channel geometry is influenced by the previous water and sediment conditions. Zhang et al. (1998; 2002) studied channel evolution in the downstream reaches after dam construction on the Yellow River and found that the water and sediment processes in the early stage after dam construction along with the characteristics of previous channel deformation can directly affect flood propagation. They also reported that both the channel-forming discharge and the river pattern can be influenced by the previous water and sediment conditions in the preceding several years (Zhang et al., 1994; Zhang et al., 1996). Subsequently, Liang et al. (2005) found that channel geometry was affected by both the current and previous water and sediment conditions. The authors also developed the empirical relationships between channel morphological variables and the characteristic parameters of incoming water-sediment re- 
gimes during previous several years, in which the accumulation effects of historical water-sediment series were preliminarily considered. Later on, Chen et al. (2006) also empirically analyzed the responses of channel bankfull dimensions to the flow and sediment conditions of the preceding several years in the lower Yellow River. To overcome the shortcomings of empirical approaches in quantifying the effects of previous flow and sediment conditions, Wu et al. $(2008 ; 2012)$ proposed the delayed response model based on the rate law of fluvial processes. This model assumes that the change rate of a characteristic channel variable is proportional to the difference between the current value and the new equilibrium value (Knighton, 1998). Wu et al. $(2008 ; 2012)$ accounted for previous effects by treating the adjusted result for each time step as the initial condition for the next time step. Using this approach, they successfully predicted the temporal changes in bankfull discharge and bankfull area in the lower Yellow River. However, the delayed response model is a conceptual model and still has difficulties in explaining the physical mechanisms of accumulation phenomena in fluvial processes.

Numerous studies have also been carried out to investigate the spatial changes in fluvial systems following disturbances. Based on long-term water and sediment observations and corresponding topographic data, Jia (1992) and Yang et al. (2017) explored the morphological changes of cross-sections along the channel downstream of the Danjiangkou Reservoir and the Three Gorges Reservoir, respectively. Wang et al. $(2004 ; 2007)$ investigated the influence of the rising Tongguan's elevation in the evolution of riverbed in lower Weihe River based on extensive field survey data. The authors demonstrated that the rising Tongguan's elevation caused retrogressive siltation waves in the lower Weihe River, and the waves propagated at a speed of approximately $10 \mathrm{~km} / \mathrm{yr}$. While these studies suggest that the influence of external disturbances can propagate with the form of waves in fluvial systems, the corresponding mathematical description has not yet been reported.

In general, previous studies have concentrated on the adjustment characteristics of cumulative channel variables (e.g., accumulated sedimentation, channel bank-full dimensions), which directly reflect the cumulative effects of previous water-sediment conditions. Based on these studies, it can be concluded that accumulation characteristics are inherent in fluvial processes, and it is reasonable to think that the accumulation effects of water and sediment conditions in the early period played an essential role in river evolution. Many studies have demonstrated that the channel geometry is affected by both current and past water and sediment conditions. However, most previous studies accounted for the cumulative effects of historical water-sediment conditions using the arithmetic mean, sliding mean, and numerical iteration methods, which cannot depict the physical patterns or fundamentally reveal the physical mechanisms of accumulation phenomena in fluvial processes. Furthermore, few studies have considered the spatial propagation characteristics of responses to external disturbances. In this study, we seek to (1) provide a mathematical description of the accumulation phenomena resulting from internal responses to external disturbances in fluvial processes and (2) develop a comprehensive theoretical model for simulating the spatiotemporal readjustments of characteristic river variables based on the stochastic theory in statistical mechanics. The proposed models are then applied to investigate the spatiotemporal readjustments of the upper and lower reaches of the rivers following the construction of dams. The results provide the theoretical basis and a new calculation method for quantitatively 
describing the spatiotemporal readjustments of non-equilibrium fluvial channels following disturbances.

\section{Accumulation phenomena in fluvial processes}

\subsection{Study cases}

Field observations of the upstream and downstream reaches of dams on several representative fluvial channels (the Colorado River and Missouri River in the United States, and the Yellow River, Yangtze River, and Hanjiang River in China) were collected. The corresponding characteristic river parameters of the studied cross-sections and channel reaches are shown in Table 1. The lengths of the studied channel reaches vary from a few kilometers to several hundred kilometers, and the magnitude of runoff also varies widely among different reaches. Among the studied rivers, the Yangtze River has the largest annual runoff followed by the Yellow River and Hanjiang River; the Colorado River and Missouri River have less annual runoff. Based on the collected field observations, the morphological characteristics of the rivers, including accumulated riverbed degradation, channel width, and accumulated erosion amount were selected as representative parameters to investigate the lateral, vertical, longitudinal, and overall spatiotemporal readjustments of the upper and lower reaches of dams.

Table 1 Characteristic river parameters for the studied cross-sections and channel reaches (Williams and Wolman, 1987; Jia, 1992; Peng et al., 2016; Yang et al., 2017)

\begin{tabular}{|c|c|c|c|c|c|c|c|c|}
\hline Project & River & $\begin{array}{l}\text { Average pre- } \\
\text { dam daily } \\
\text { discharge } \\
\left(\mathrm{m}^{3} / \mathrm{s}\right)\end{array}$ & $\begin{array}{l}\text { Average post- } \\
\text { dam daily } \\
\text { discharge } \\
\left(\mathrm{m}^{3} / \mathrm{s}\right)\end{array}$ & $\begin{array}{c}\text { Studied } \\
\text { cross-section or } \\
\text { reach }\end{array}$ & $\begin{array}{c}\text { Distance } \\
(\mathrm{km})\end{array}$ & Variable & $\begin{array}{l}\text { Survey } \\
\text { period }\end{array}$ & $\begin{array}{l}\text { Survey } \\
\text { number }\end{array}$ \\
\hline Hoover & \multirow{3}{*}{ Colorado } & 520 & 400 & CHD-1-CHD-3 & $10-36$ & \multirow{3}{*}{$\begin{array}{l}\text { River- } \\
\text { bed } \\
\text { degra- } \\
\text { dation }\end{array}$} & $1935-1948$ & 15 \\
\hline Parker & & 230 & 340 & CPD-1-CPD-3 & $39-95$ & & $1938-1975$ & 16 \\
\hline Davis & & 400 & 340 & CDD-1-CDD-2 & $1-9$ & & $1948-1975$ & 28 \\
\hline Fort Peck & \multirow{3}{*}{ Missouri } & 200 & 280 & MFP-1-MFP-3 & $9-75$ & \multirow{3}{*}{$\begin{array}{l}\text { Chan- } \\
\text { nel } \\
\text { width }\end{array}$} & $1936-1973$ & 8 \\
\hline Garrison & & 600 & 660 & MGD-1-MGD-3 & $32-54$ & & 1949-1976 & 6 \\
\hline Gavins Point & & 930 & 740 & MGP-1-MGP-3 & $7-48$ & & 1955-1974 & 5 \\
\hline Danjiangkou & Hanjiang & 1335 & 1091 & HJG-HZ & $3-270$ & $\begin{array}{l}\text { Water } \\
\text { level }\end{array}$ & $1960-1976$ & 6 \\
\hline \multirow{2}{*}{ Sanmenxia } & \multirow{2}{*}{ Yellow } & \multirow{2}{*}{1522} & \multirow{2}{*}{1412} & XLD-LJ & $61-678$ & \multirow{4}{*}{$\begin{array}{l}\text { Accu- } \\
\text { mu- } \\
\text { lated } \\
\text { erosion } \\
\text { and } \\
\text { depo- } \\
\text { sition } \\
\text { amount }\end{array}$} & $1961-1984$ & 21 \\
\hline & & & & SZ-TG & - & & $1965-1984$ & 20 \\
\hline Xiaolangdi & Yellow & 1266 & 807 & XLD-LJ & $61-678$ & & $2000-2015$ & 16 \\
\hline $\begin{array}{l}\text { Three } \\
\text { Gorges }\end{array}$ & Yangtze & 14027 & 12873 & $\mathrm{YC}-\mathrm{HK}$ & $30-807$ & & 2003-2016 & 14 \\
\hline
\end{tabular}

The distance in the sixth column in Table 1 is the distance between each studied cross-section or the middle point of the studied channel reach and the dam site.

\subsection{Adjustment of characteristic river parameters}

\subsubsection{Vertical adjustment}

Dam construction on rivers tends to destroy the previous equilibrium state and trigger the 
riverbed reformation of the lower reaches downstream of the dam (Chien, 1985). Due to the water storage and sediment detention in the reservoir, the flow and sediment regimes entering the lower reaches are greatly altered, that is, the suspended sediment concentration in the lower reaches is much lower after dam installation, while the sediment transport capacity is higher. Consequently, the lower reaches generally undergo significant riverbed incision because of the insufficient material input. Herein, the temporal variations in accumulated riverbed degradation in the studied cross-sections downstream of the Hoover Dam, Parker Dam, and Davis Dam are considered to investigate vertical adjustment in downstream reaches following dam construction.

Temporally, the riverbed in downstream reaches showed significant erosion and incision, and the accumulated riverbed degradation gradually increased over time (Figure 1). Ten years after dam construction, the equilibrium degradation depths in the three studied cross-sections downstream of the Hoover Dam were approximately $4.5 \mathrm{~m}, 2.6 \mathrm{~m}$, and $2.4 \mathrm{~m}$; The corresponding depths in the three studied cross-sections downstream of the Parker Dam were approximately $3.8 \mathrm{~m}, 2.7 \mathrm{~m}$, and $1.0 \mathrm{~m}$, while those of the two cross-sections downstream
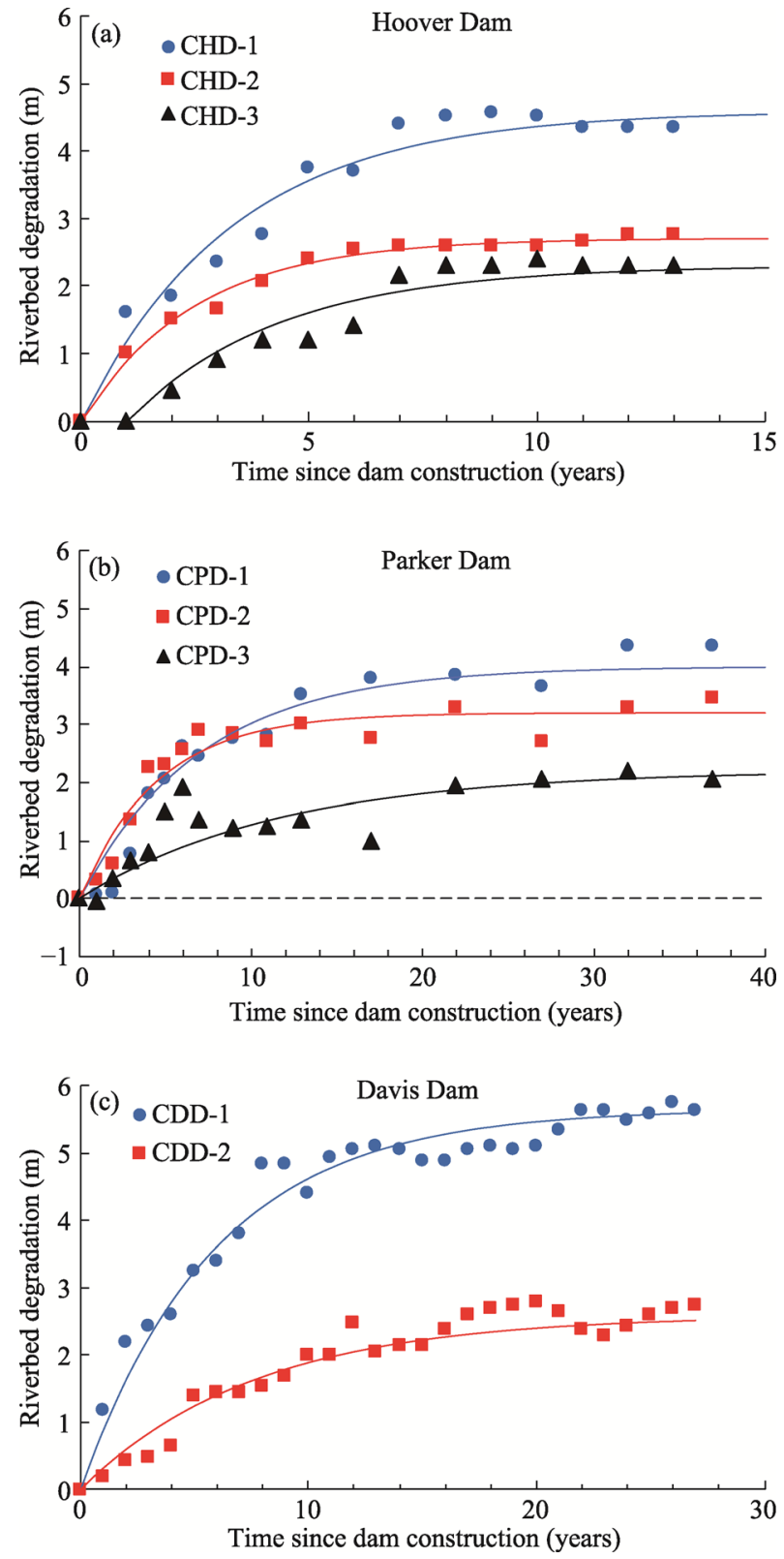

Figure 1 Accumulated riverbed degradation in the studied cross-sections downstream of dams on the Colorado River

of the Davis Dam 20 years after dam construction were about $5.1 \mathrm{~m}$ and $2.8 \mathrm{~m}$. Notably, the adjustment rate was the largest in the first 5 years after dam construction, and nearly half of the eventual equilibrium values were attained during this time. Between approximately 10 and 20 years after dam construction, the accumulated riverbed degradation still fluctuated slightly over time; however, the fluctuation range was small, and the vertical adjustment could be regarded as generally completed. Spatially, the upper cross-sections tended to erode earlier and had larger accumulated riverbed degradation than the lower cross-sections. 
For example, cross-section CHD-1, which is much closer to the dam site than the other cross-sections, began to erode immediately after dam construction, and the equilibrium depth was $4.5 \mathrm{~m}$ (Figure 1a); in contrast, for cross-section CHD-3, which is farther away from the dam site, riverbed incision began one year after dam construction, and the equilibrium depth was $2.4 \mathrm{~m}$.

\subsubsection{Lateral adjustment}

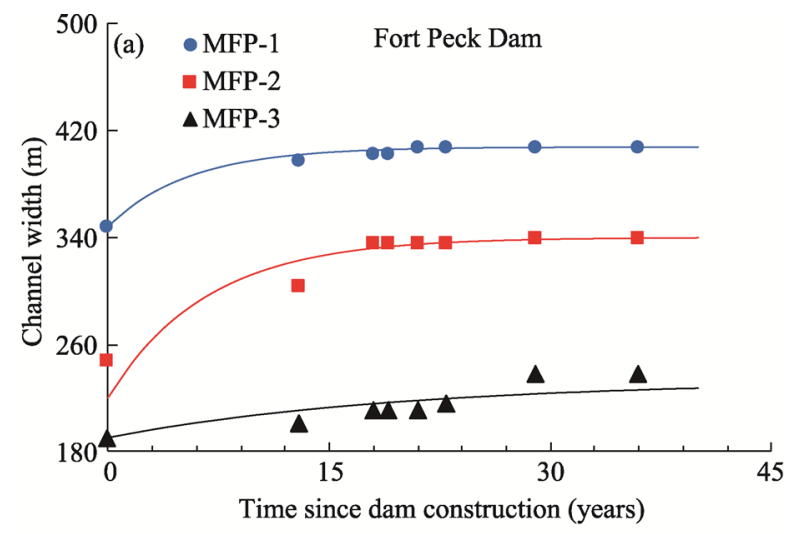

As mentioned previously, the amount of sediment entering the reaches downstream of a dam is dramatically reduced by the operation of the reservoir. If the mainstream still oscillates in the lateral direction, and the erosion resistance of the channel bank is relatively poor, significant collapse may occur in the floodplain, leading to considerable widening of the fluvial channel (Qian et al., 1987). For

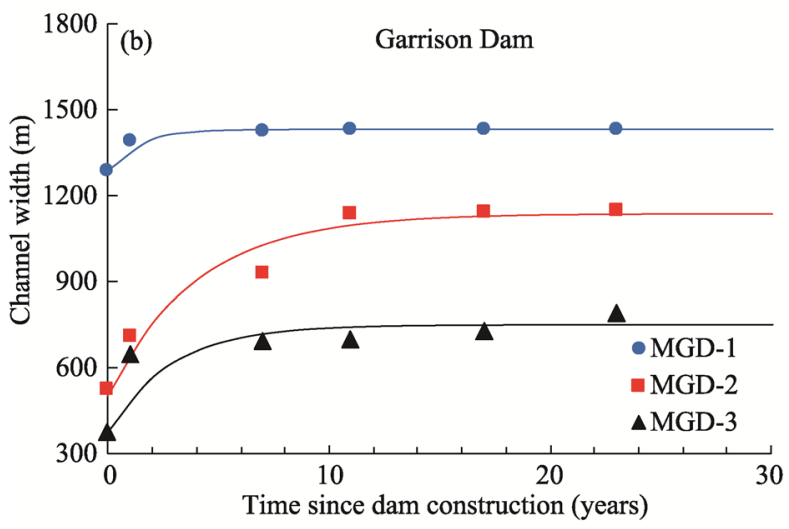
example, following dam construction on the Missouri River in the United States, the long-term release of clear water triggered a large number of bank collapses in the downstream reaches. These collapses were accompanied by the strong erosion of high beaches and severe deposition in lower beaches, and the channel geometry eventually showed significant widening compared to before dam construction (Rahn, 1977). In this

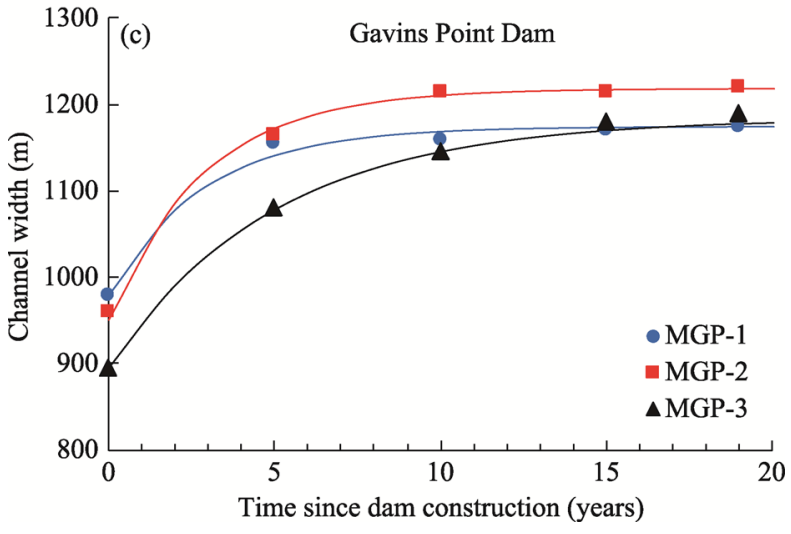

Figure 2 Changes in channel width after dam construction in the studied cross-sections downstream of dams on the Missouri River paper, the lateral adjustment of the downstream reaches of dams was comprehensively analyzed based on the collected field observations. Figure 2 shows the temporal variation in the channel widths of the studied cross-sections located downstream of the Fort Peck Dam, Garrison Dam, and Gavins Point Dam. The channel widths in the studied cross-sections changed greatly over time, particularly in the period immediately after dam construction. The widening rate then gradually declined over time 
until the eventual dynamic equilibrium state was reached. Here, the dimensionless quantity $r_{w}$ is defined as the relative widening rate of the studied cross-sections; $r_{w}=\left(W_{e}-W_{0}\right) / W_{0}$, where $W_{e}$ and $W_{0}$ are the asymptotic and initial channel widths. The relative widening rate $r_{w}$ varied significantly among the studied cross-sections downstream of the Garrison Dam (Figure $2 \mathrm{~b}$ ), the $r_{w}$ values along the channel were $10.9 \%, 119.0 \%$, and $110.1 \%$, corresponding to width changes of $140 \mathrm{~m}, 625 \mathrm{~m}$, and $414 \mathrm{~m}$, respectively. In comparison, the relative widening rates in the studied cross-sections downstream of the Fort Peck Dam (Figure 2a) and the Gavins Point Dam (Figure 2c) showed much smaller variations, with average $r_{w}$ values of $26.5 \%$ and $26.6 \%$, corresponding to width changes of $67 \mathrm{~m}$ and $250 \mathrm{~m}$, respectively. Due to the complex relationships among the lateral adjustment behavior, the composition of the bank, the erosion resistance of the bank, and the reservoir operation mode, the widening properties and widening rates vary greatly among different channel reaches.

\subsubsection{Longitudinal adjustment}

The altered flow and sediment regimes caused by reservoir operation usually induce considerable readjustment of the longitudinal profile in reaches downstream of a dam site. With the development of riverbed erosion, the suspended sediment concentration in the lower reaches gradually recovers along the channel, and the erosion intensity declines. In this study, the longitudinal readjustments of downstream reaches after dam construction were investigated based on the observed water levels in typical cross-sections downstream of the Danjiangkou Reservoir along with the accumulated erosion amounts in channel reaches downstream of the Sanmenxia Reservoir, Xiaolangdi Reservoir, and Three Gorges Reservoir (Figure 3; positive and negative values of accumulated erosion indicate erosion and buildup, respectively). Figure $3 \mathrm{a}$ shows the change in water level along the channel downstream of the Danjiangkou Reservoir. Some points in Figure 3a are derived from linear interpolation because the observation time was not completely consistent among cross-sections. Figures $3 \mathrm{~b}-3 \mathrm{~d}$ show the longitudinal distributions of accumulated erosion amount in reaches downstream of the Sanmenxia Reservoir, Xiaolangdi Reservoir, and Three Gorges Reservoir, respectively. Temporally, the downstream reaches experienced continuous erosion, and the accumulated erosion amount gradually increased over time after dam construction, while the accumulation rate declined. Spatially, the erosion intensity in the studied reaches generally decreased along the channel. The erosion intensity was the strongest near the dam, and then decreased nonlinearly as the distance from the dam increased.

The erosion quantity was much larger in the HYK-GC Reach (Huayuankou-Gaocun Reach; that is HJ Reach and JG Reach in Figure 3b) downstream of the Sanmenxia Reservoir and the HYK - JHT Reach (HJ Reach in Figure 3c) downstream of the Xiaolangdi Reservoir on the Yellow River. Significant riverbed erosion in these regions maybe caused by the characteristics of the braided channel, which include frequent oscillations and erratic migration (Xu and Zhang, 2000; Wang, 2003). According to statistics, the middle diameter of the riverbed material in the HYK-GC Reach is only approximately $0.09 \mathrm{~mm}$, while the channel slope reaches $2 \%$. Due to the steep channel slope, rapid flow, and fine sediment particles, the sandbars and banks usually move rapidly, and riverbed deformation is strong (Chien et al., 1961). In addition, the sharp decrease in erosion amount in the CLJ-WH Reach (Chenglingji-Wuhan Reach; that is CW Reach in Figure 3d) of the Yangtze River 
may be related to the relatively gentle channel slope in this reach, which results in a relatively small flow velocity and insufficient sediment transport capacity, in contrast to its upstream reaches (Fu et al., 2005).
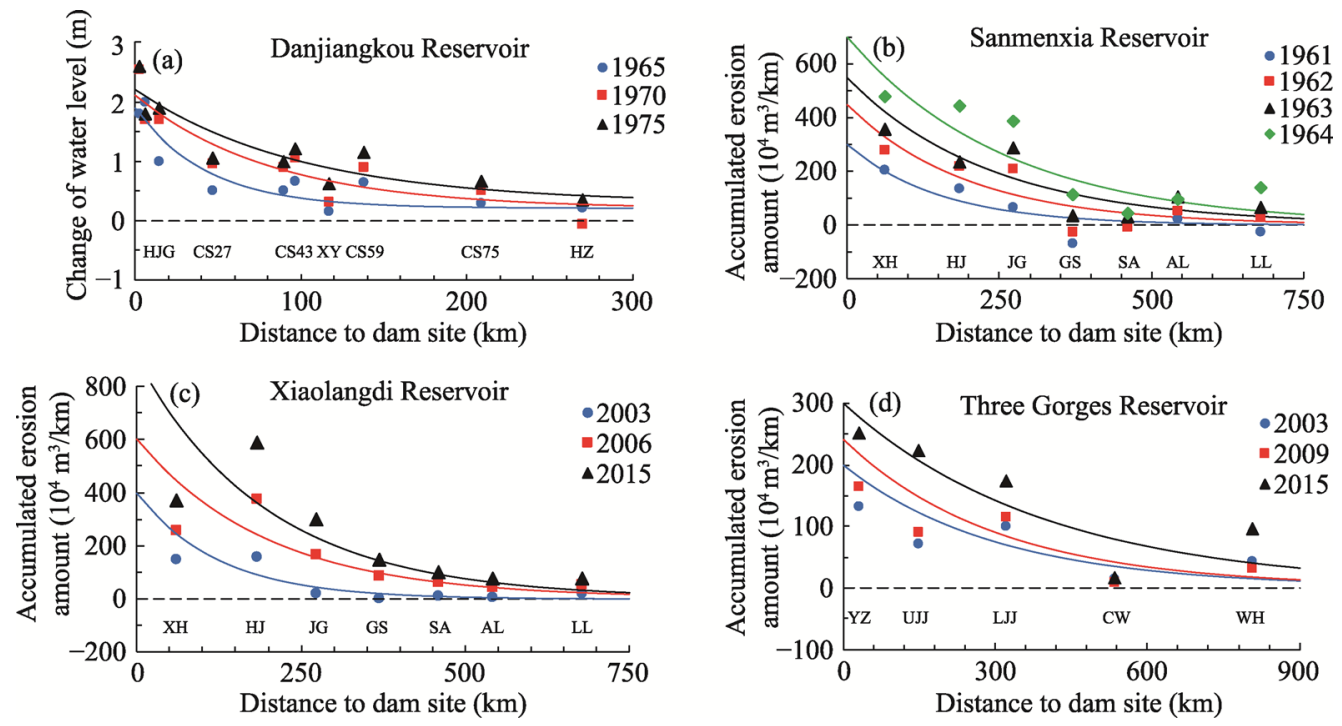

Figure 3 Longitudinal adjustment of the studied channel reaches downstream of dams

\subsubsection{Overall adjustment in the entire reach}

The Sanmenxia Reservoir has experienced serious sedimentation since dam construction. To reduce the sedimentation rate in the reservoir area, several sediment management strategies have been implemented. These include twice project reconstructions (July 1966-August 1968 and December 1970-December 1973) and three changes in operation modes. The operation modes were as follows: storage mode (September 1960-March 1962), flood detention mode (April 1962-October 1973), and controlled release mode (since November 1973) (Wang et al., 2005). However, due to the imbalance in incoming water and sediment conditions (i.e., little water but a lot of sediment), the reservoir area has shown a continuous silting trend through the 21 st century. With the release of a large amount of sediment from the reservoir area accompanied by the construction of production dikes in the downstream beaches and extensive use of the Yellow River sluice gates, the lower Yellow River has continued to deteriorate with serious sedimentation and shrinkage of the mainstream (Liu, 2005; Pang, 2005). Considering the effects of dam reconstructions and changes in operation mode, the field data from Sizhan Station to Tongguan Station in the Sanmenxia Reservoir area from 1965 to 1984 were selected to investigate the development of sedimentation in the reservoir area. Meanwhile, to analyze the factors affecting sedimentation in the lower Yellow River, the field data from 1968 to 1984 were also selected based on the changes in operation mode mentioned previously. Based on the adjustment of operation mode in 1973 and the delayed response in fluvial properties, the measured data of the lower channel were divided into two periods.

Figure 4 shows the temporal variations in sedimentation in the Sanmenxia Reservoir area 
and the lower Yellow River. The accumulated sediment amounts in both the reservoir area upstream Tongguan Station and the entire lower Yellow River generally increased over time with a larger sedimentation rate at first followed by a smaller one. The fluvial systems gradually approached dynamic equilibrium during the studied period. Since the operation mode of the Sanmenxia Reservoir changed from flood detention mode to controlled release mode, an obvious inflection point appears in Figure $4 \mathrm{~b}$. The fundamental reason for this phenomenon is the significant variations in water and sediment conditions entering the lower Yellow River due to changes in both the natural inflow conditions and the reservoir operation mode. When in flood detention mode, because of the imbalanced incoming water and sediment conditions and the operation of additional discharge facilities after 1966, part of the sediment deposited in the reservoir area in the early stage was washed out in the process of reducing the water level, resulting in a sharp increase in the sediment concentration of flow entering the downstream channel reaches. Since the Sanmenxia Reservoir entered into controlled release mode (i.e., storing the relatively clear water in non-flood months from November to June and releasing turbid water in flood months), the inflow conditions have been much more favorable. Sediment deposition still occurred but with a lower total silting amount in the downstream channel (Zhao et al., 1989).
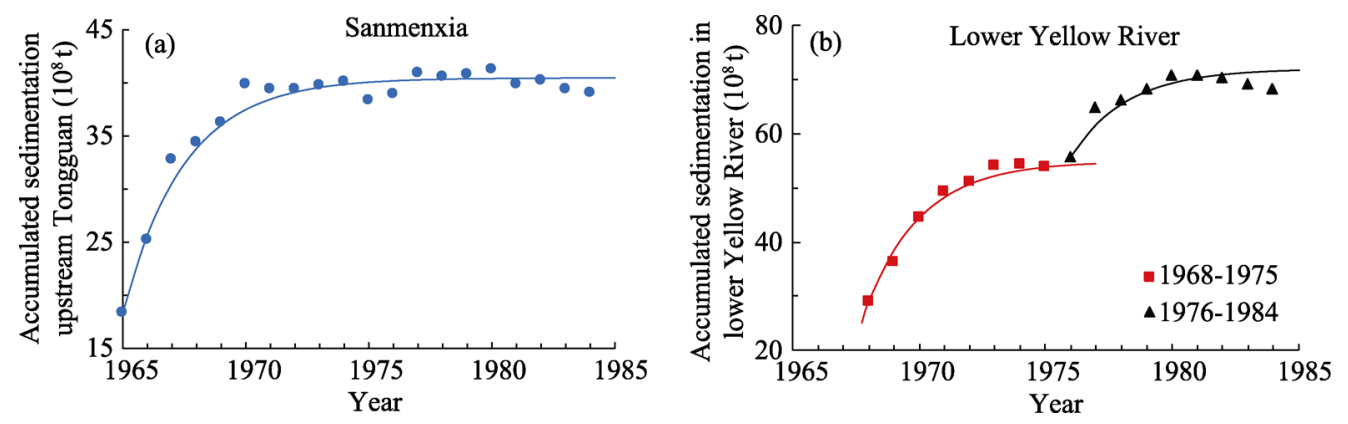

Figure 4 Accumulated sedimentation in the Sanmenxia Reservoir area and lower reaches of the Yellow River

As mentioned previously, the spatiotemporal adjustments of the reaches upstream and downstream of dams in fluvial channels were analyzed comprehensively. The vertical, lateral, longitudinal, and overall adjustments indicate the following. Temporally, the adjustment rates of morphological variables were large in the first few years after dam construction and then declined rapidly over time. The accumulated riverbed degradation, channel width, and accumulated sedimentation amount continuously increased until a new dynamic equilibrium was reached. These phenomena reflect the representative accumulation characteristics of fluvial processes. Spatially, the erosion intensity in the downstream reaches decreased nonlinearly along the channel until eventually diminishing. The imbalanced spatial distribution of erosion intensity arose from the property of system response characterized by propagation in space but decay over time, which is an external manifestation of accumulation characteristics in fluvial processes after a disturbance. It can be concluded that accumulation is an inherent property of fluvial processes and must be considered when studying the evolution of rivers. 


\section{Theoretical framework}

Under the effects of external disturbances, the establishment of a new dynamic equilibrium in a river via self-regulatory behavior is essentially the accumulation of continuous internal responses induced by external disturbances over time. In this study, accumulation effects were studied based on the stochastic theory proposed by Gardiner (2009). First, the accumulation action generated by external disturbances in fluvial processes can be described as

$$
I(t)=\sum_{t_{k}} F\left(t-t_{k}\right),
$$

where $I(t)$ is the accumulation action, which represents the accumulated effects of external disturbances and can be regarded as a characteristic parameter of fluvial channels; $F(t)$ is the response intensity induced by an individual disturbance; and $t_{k}$ is the time at which a disturbance occurs. The accumulation of internal responses caused by external disturbances is shown in Figure 5. To determine the mathematical expression for quantity $I(t)$, two crucial factors must be considered: the probability distribution of

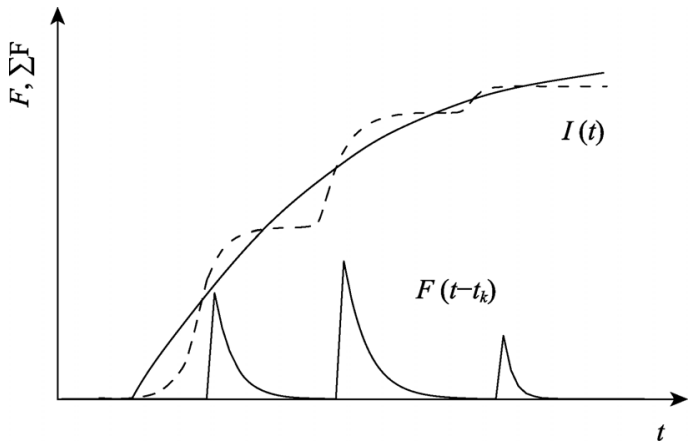

Figure 5 Diagram showing the accumulation effects of external disturbances in fluvial processes external disturbances and the relationship between $F(t)$ and time.

Riverbed adjustment mainly occurs during flood seasons (Wu et al., 2008; Xia et al., 2014a; Xia et al., 2014b); that is, the floods during flood seasons are the most common disturbance affecting riverbed evolution. Thus, the frequency of external disturbances $N(t)$ (i.e., floods during the flood seasons) is assumed to conform to a Poisson distribution. The incremental function $\mu(t)$ is defined as

$$
\mu(t)=d N(t) / d t
$$

$N(t)$ always equals zero unless it increases by one in micro time internal $\mathrm{d} t$. In other words, $\mu(t)$ has the property of a Dirac delta function (i.e., $\left.\int_{-\infty}^{\infty} \mu(t) d t=1\right)$. Therefore, the integral form of accumulation action $I(t)$ can be expressed as

$$
I(t)=\int_{-\infty}^{\infty} F\left(t-t^{\prime}\right) \mu\left(t^{\prime}\right) d t^{\prime} .
$$

Notably, when both $t<0$ and when $t \rightarrow \infty$, the internal response intensity $F(t)$ that is the initial adjustment rate of a characteristic river variable equals zero; that is, the fluvial channel does not respond when an external disturbance has not yet occurred or a long time has passed since the external disturbance. As shown in previous studies, the responses of rivers commonly follow the law of exponential decay. For example, the development of gullies under substantial climatic changes (Graf, 1977), adjustment of channel geometry following natural meander cutoffs (Hooke, 1995), changes in riverbed slope after channelization (Rinaldi, 2003), and adjustment of riverbed elevation after volcanic eruption (Simon and Thorne, 1996) all show typical characteristics of exponential decay over time. Hence, the 
response intensity $F(t)$ resulting from an individual disturbance obeys the following functional relationship

$$
F(t)= \begin{cases}q e^{-\alpha t} & (t \geqslant 0) \\ 0 & (t<0)\end{cases}
$$

where $q$ is the initial response intensity (i.e., the initial adjustment rate of a characteristic channel parameter); and $\alpha$ is the attenuation coefficient of response intensity, which varies widely between rivers and reflects the climate and water-sediment properties. The external disturbance causes an imbalance between sediment transport capacity and the previous sediment concentration; this is the basic driving force of the readjustment of the riverbed. A large $\alpha$ value corresponds to a fast decline in the above imbalance and a fast adjustment of the river to the disturbance (i.e., the new dynamic equilibrium state is reached quickly). For the convenience of calculation, $\alpha$ is assumed to be a constant.

Substituting equation (4) into equation (3) gives

$$
I(t)=\int_{-\infty}^{t} d t^{\prime} q e^{-\alpha\left(t-t^{\prime}\right)} \frac{d N\left(t^{\prime}\right)}{d t^{\prime}} .
$$

Taking the derivative of accumulation action $I(t)$ with respect to time $t$ gives

$$
\frac{d I(t)}{d t}=-\int_{-\infty}^{t} d t^{\prime} \alpha q e^{-\alpha\left(t-t^{\prime}\right)} \frac{d N\left(t^{\prime}\right)}{d t^{\prime}}+\left[q e^{-\alpha\left(t-t^{\prime}\right)} \frac{d N\left(t^{\prime}\right)}{d t}\right]_{t^{\prime}=t} .
$$

Equation (6) can be simplified into

$$
\frac{d I(t)}{d t}=-\alpha I(t)+q \mu(t)
$$

Equation (7) is a stochastic differential equation, and the driving force is provided by the term on the right. Equation (7) indicates that the adjustment rate of a characteristic river variable is related to the magnitude of the response intensity, the attenuation rate, and the frequency of the external disturbance.

The fluctuation quantity $\eta(t)$ is defined as the difference between $d N(t)$ and its mean value:

$$
\eta(t)=d N(t)-\lambda d t
$$

Equation (7) can be transformed into

$$
d I(t)=-\alpha I(t) d t+q \mu(t) d t .
$$

Substitute $\mu(t)=d N(t) / d t$ and $\eta(t)=d N(t)-\lambda d t$ into equation (9) gives

$$
d I(t)=[\lambda q-\alpha I(t)] d t+q d \eta(t) .
$$

Taking the expectation of both sides of equation (10) and considering that $\langle q d \eta(t)\rangle=0$, one obtains

$$
\frac{d\langle I(t)\rangle}{d t}=\lambda q-\alpha\langle I(t)\rangle .
$$

Taking the limit $t \rightarrow \infty$, the equilibrium value of the characteristic channel variable adjusted towards can be expressed as

$$
\langle I(\infty)\rangle=\lambda q / \alpha
$$

Then, the first-order ordinary differential equation of accumulation effects can be ob- 
tained as

$$
\frac{d\langle I(t)\rangle}{d t}=\alpha\langle I(\infty)\rangle-\alpha\langle I(t)\rangle .
$$

Equation (13) indicates that after an external disturbance, the adjustment rate of a characteristic river variable will gradually decrease as the equilibrium value is approached. That is, the fluvial system gradually moves toward the new equilibrium state. By solving equation (13), the theoretical model for the temporal adjustment of characteristic river parameters can be obtained as follows:

$$
\langle I(t)\rangle=\left(1-e^{-\alpha t}\right)\langle I(\infty)\rangle+e^{-\alpha t}\left\langle I_{0}\right\rangle .
$$

where $\langle I(\infty)\rangle$ is the asymptotic value of a characteristic cumulative river variable; $\langle I(t)\rangle$ is the value of that variable at time $t$; and $\left\langle I_{0}\right\rangle$ is the initial value of the variable at $t=0$. Equation (14) can be used to describe the readjustments of characteristic river parameters over time following a disturbance. The values of the coefficient $\alpha$ and equilibrium value $\langle I(\infty)\rangle$ are generally related to the water-sediment properties, the composition of the riverbed, and the geologic and climatic characteristics of the river basin. The form of equation (14) is consistent with the delayed response model (Knighton, 1998; Richard, 2001; Wu and Zheng, 2012). Essentially, the delayed response model is a particular solution derived from the principle of accumulation properties in fluvial processes by assuming that the frequency of an external disturbance conforms to a Poisson distribution, and that the response intensity caused by an individual disturbance satisfies the law of exponential attenuation.

Next, we studied the spatial distributions of responses to external effects to provide a scientific basis for predicting the spatial adjustments of river morphological variables after disturbances. The accumulation action $\langle I(t)\rangle$ is a function of both spatial and temporal factors, where the position in space is also related to time $t$. Thus equation (14) can be transformed into

$$
\frac{d\langle I\rangle}{d t}=\frac{d\langle I\rangle}{d x} \frac{d x}{d t}=\alpha\langle I(\infty)\rangle-\alpha\langle I\rangle .
$$

Substituting $v=d x / d t$ into equation (15) gives

$$
v \frac{d\langle I\rangle}{d x}=\alpha\langle I(\infty)\rangle-\alpha\langle I\rangle .
$$

By solving equation (16), a theoretical model for the spatial adjustments of characteristic river parameters can be obtained as follows:

$$
\langle I(x)\rangle=\left(1-e^{-\alpha x / v}\right)\langle I(\infty)\rangle+e^{-\alpha x / v}\left\langle I_{x 0}\right\rangle .
$$

where $v$ is the propagation velocity of external effects; $\alpha / v$ is the spatial attenuation coefficient; $\left\langle I_{x 0}\right\rangle$ is the value of a characteristic parameter at the initial position; and $\langle I(\infty)\rangle$ is the corresponding equilibrium value of that. Equation (17) can be used to describe the readjustments of characteristic river parameters along the channel after a disturbance. The propagation velocity $v$ is also related to the water-sediment properties, the composition of the riverbed, and the climatic characteristics of the basin. For example, 12.3 years after the construction of the Milburn Dam in the United States, the downstream scour reached $7.4 \mathrm{~km}$ away 
from the dam site; in contrast, four years after the construction of the Hoover Dam, the downstream scour reached $117 \mathrm{~km}$ from the dam site (Williams and Wolman, 1987). Thus, the spatial and temporal scales of the cumulative response are closely related to the basin properties and strength of the disturbance.

\section{Model application}

\subsection{Dimensionless equation}

Through equation transposition and deformation, the theoretical models proposed above for simulating the spatiotemporal readjustments of characteristic river variables can be nondimensionalized as

$$
\frac{\langle I(t)\rangle-\left\langle I_{t_{0}}\right\rangle}{\langle I(\infty)\rangle-\left\langle I_{t_{0}}\right\rangle}=\left(1-e^{-\alpha t}\right)
$$

and

$$
\frac{\langle I(x)\rangle-\left\langle I_{x_{0}}\right\rangle}{\langle I(\infty)\rangle-\left\langle I_{x_{0}}\right\rangle}=\left(1-e^{-\alpha x / v}\right)
$$

The term on the left side of equation (18) represents the relative readjustment of the characteristic variable over time with respect to the values at $t=0$ and in the new equilibrium state. Correspondingly, the left side of equation (19) represents the relative readjustment of the characteristic variable along the channel with respect to the value at the disturbance point where the system response has not yet started declining and the value where the effects of the external disturbance have vanished completely.

\subsection{Simulation of spatiotemporal adjustments}

When using the above theoretical models to simulate the spatio-temporal readjustments of characteristic river variables, the undetermined model parameters need to be calibrated. Based on observed hydrological measurements, the values of $\alpha$ and $\alpha / v$ for each studied cross-section and channel reach were obtained via nonlinear regression analysis (Tables 2 and 3).

The values of relative adjustment for each set of measured data can be obtained via equation deforming referring to the left dimensionless term shown in the above equation (18) and equation (19) based on the calibrated model parameters. The dimensionless points were then divided into four types: vertical readjustment, lateral readjustment, longitudinal readjust-

Table 2 Parameter values in equation (18)

\begin{tabular}{cccccc}
\hline $\begin{array}{c}\text { Vertical } \\
\text { readjustment }\end{array}$ & $\alpha$ & $\begin{array}{c}\text { Lateral } \\
\text { readjustment }\end{array}$ & $\alpha$ & $\begin{array}{c}\text { Overall readjustment } \\
\text { (entire reach) }\end{array}$ & $\alpha$ \\
\hline CHD-1-CHD-3 & $0.30,0.40,0.30$ & MGP-1-MGP-3 & $0.40,0.45,0.50$ & SZ-TG & 0.40 \\
CPD-1-CPD-3 & $0.14,0.22,0.09$ & MFP-1-MFP-3 & $0.18,0.15,0.05$ & LYR (1968-1975) & 0.45 \\
CDD-1-CDD-2 & $0.17,0.16$ & MGD-1-MGD-3 & $0.60,0.25,0.40$ & LYR (1976-1984) & 0.40 \\
\hline
\end{tabular}

LYR in Table 2 represents all lower reaches of the Yellow River. 
Table 3 Parameter values in equation (19)

\begin{tabular}{cc}
\hline $\begin{array}{c}\text { Longitudinal } \\
\text { readjustment }\end{array}$ & \multicolumn{1}{c}{$\alpha / v$} \\
\hline HJG-HZ (1965-1975) & $0.0160,0.0120,0.0090$ \\
XLD-LJ (1961-1964) & $0.0065,0.0060,0.0042,0.0038$ \\
XLD-LJ (2003-2015) & $0.0100,0.0050,0.0050$ \\
YC-HK (2003-2015) & $0.0033,0.0033,0.0025$ \\
\hline
\end{tabular}

ment, and readjustment of all channel reaches overall (Figure 6). In Figures 6a, $6 \mathrm{~b}$, and $6 \mathrm{~d}$, the abscissa is the weighted time, and the ordinate is the relative readjustment degree of the characteristic river variable (ranging from 0 to 1 ). In the dimensionless quantity $\left(\delta Z_{\mathrm{t}}-\delta Z_{0}\right) /$ $\left(\delta Z_{e}-\delta Z_{0}\right)$ in Figure $6 \mathrm{a}, \delta Z_{t}$ is the value

of riverbed degradation at time $t$, while $\delta Z_{0}$ and $\delta Z_{e}$ are the initial and asymptotic values of this parameter, respectively. Similarly, in the dimensionless quantity $\left(W_{t}-W_{0}\right) /\left(W_{e}-W_{0}\right)$ in Figure $6 \mathrm{~b}$, the variables $W_{0}, W_{t}$, and $W_{e}$ are the values of channel width at the initial time, time $t$, and equilibrium, respectively. In the dimensionless quantity $\left(\delta V_{t}-\delta V_{0}\right) /\left(\delta V_{e}-\delta V_{0}\right)$ in Figure $6 \mathrm{~d}, \delta V_{0}, \delta V_{t}$, and $\delta V_{e}$ are the values of accumulated erosion at the initial time, time $t$, and equilibrium, respectively. In contrast, in Figure $6 c$, the abscissa is the weighted distance, and the ordinate is the relative readjustment degree of the characteristic river variable along the channel; $\delta E_{0}, \delta E_{e}$, and $\delta E_{x}$ are the initial value, asymptotic value, and value at distance $x$, respectively, of accumulated erosion amount or accumulated changes in water level. The solid curves in Figure 6 are the calculated results.

The vertical, lateral, longitudinal, and overall spatiotemporal readjustments of the channels all conformed to the same unified theoretical curve. Temporally, the adjustment rates of accumulated riverbed degradation, channel width, and accumulated erosion amount in the studied cross-sections and channel reaches were much larger in the relatively earlier stage and then declined exponentially over time until new dynamic equilibrium states were reached (Figures 6a, 6b, and 6d). Spatially, the cumulative river characteristic variables (i.e., the accumulated changes in water level and accumulated erosion amounts) showed similar variations as above. As the weighted distance to the dam site increased, the rates of change in these variables decreased nonlinearly along the channel until eventually diminishing, reflecting typical negative exponential attenuation behavior (Figure $6 \mathrm{c}$ ). The determination coefficient $R^{2}$ between the measured and the calculated values for accumulated riverbed degradation, channel width, erosion amount along the channel, and sedimentation were 0.92 , $0.93,0.76$, and 0.95 , respectively, indicating generally high correlation. In general, the results suggest that the accumulation characteristics of fluvial processes and the spatial propagation characteristics of system responses must both be considered to accurately simulate the spatiotemporal readjustments of characteristic river parameters. Thus, the accumulation properties of system responses induced by external disturbances and their spatial propagation are fundamental factors affecting river evolution.

\subsection{Examples of model application}

The following cross-sections and reaches were selected as examples to investigate the spatiotemporal adjustments of rivers using the developed models: CHD-2 downstream of the Hoover Dam on the Colorado River; MFP-1 downstream of the Fort Peck Dam on the Missouri River; HJG-HZ Reach downstream of the Danjiangkou Reservoir on the Hanjiang River; and SZ-TG Reach in the Sanmenxia Reservoir area on the Yellow River (Figure 7). 

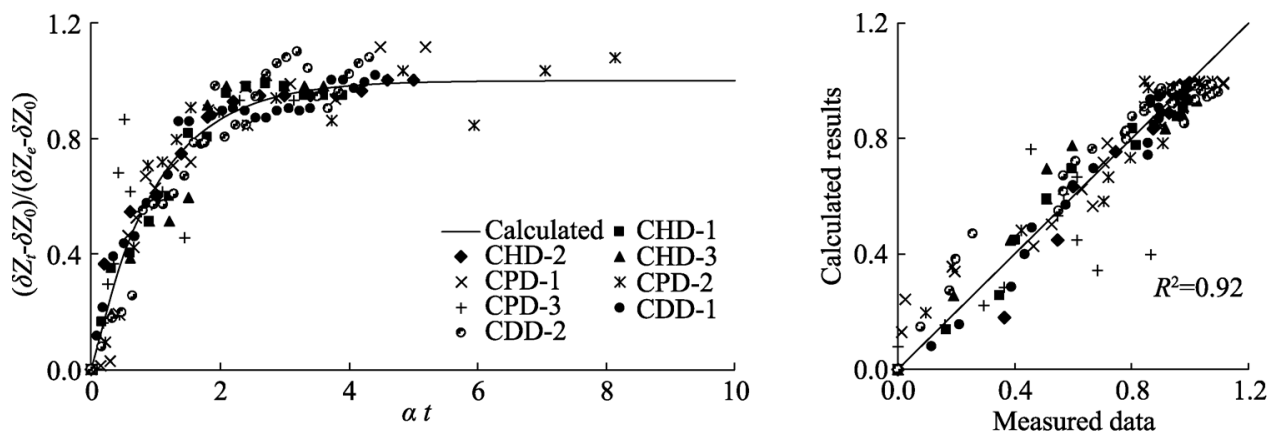

(a) Comparison between the measured and calculated values of riverbed degradation
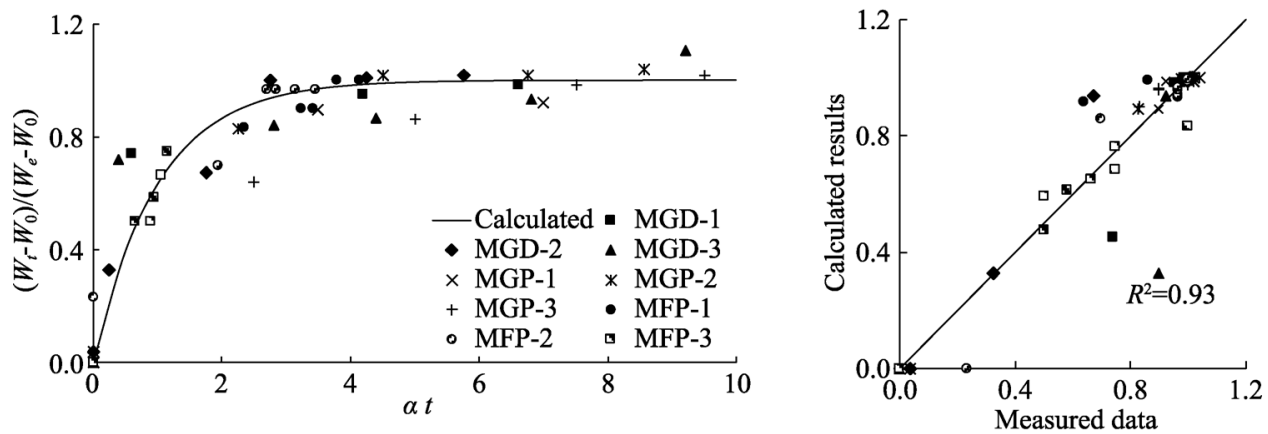

(b) Comparison between the measured and calculated values of channel width
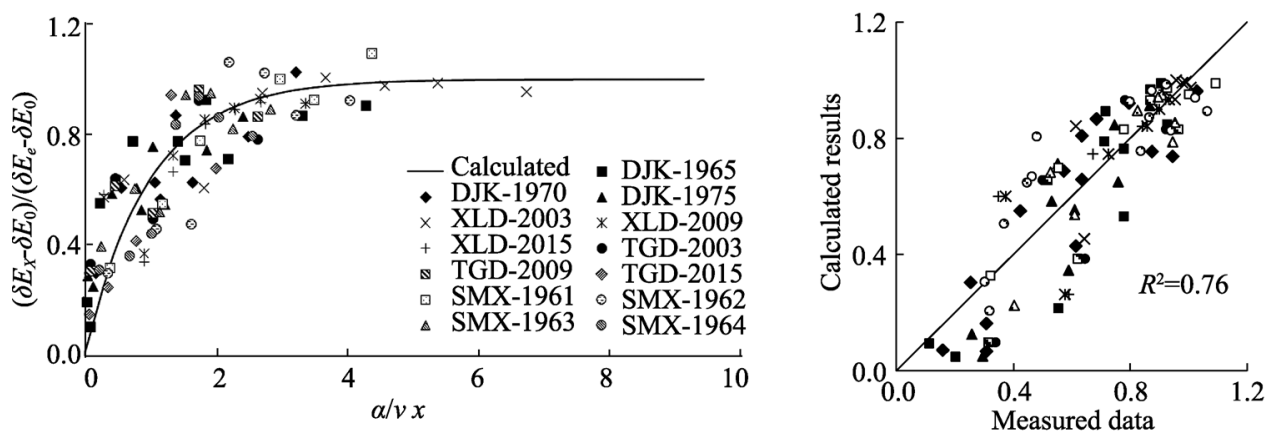

(c) Comparison between the measured and calculated values of accumulated erosion amount along the channel
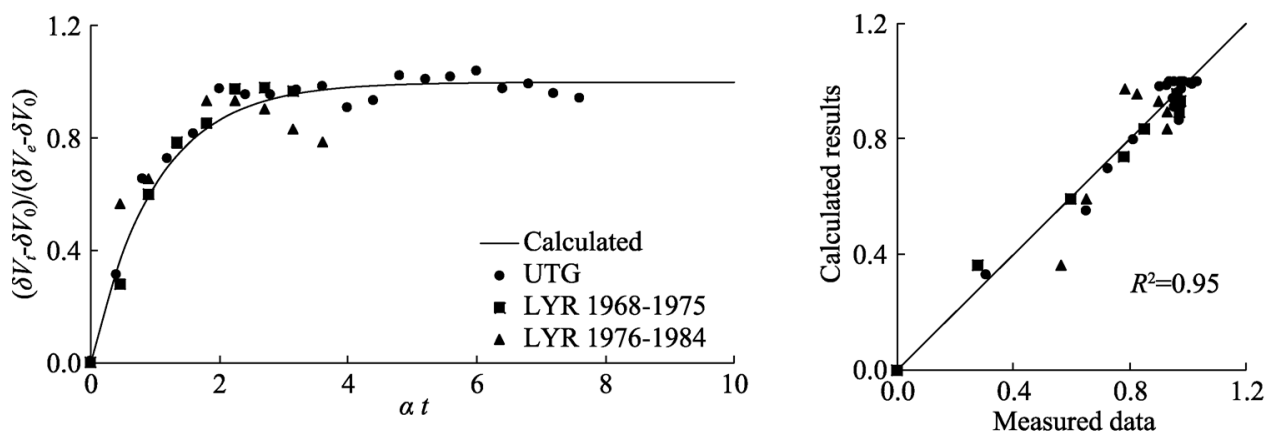

(d) Comparison between the measured and calculated values of accumulated sedimentation in reservoir and LYR

Figure 6 Comparison between the measured and calculated characteristic river variables in the studied cross-sections and channel reaches 
Figures $7 \mathrm{a}$ and $7 \mathrm{~b}$ show the changes in riverbed degradation and channel width in the CHD-2 and MFP-1 cross-sections. The adjustment rates in both the vertical and lateral directions were large in the early period after dam construction and then decreased gradually over time. The determination coefficient $R^{2}$ between the measured and calculated values was 0.99 . Figure $7 \mathrm{c}$ shows the changes in water level for different cross-sections in the HJG-HZ Reach downstream of the Danjiangkou Reservoir in $1970\left(R^{2}=0.84\right)$. Figure $7 d$ shows the accumulated sedimentation above Tongguan Station in the Sanmenxia Reservoir area over time $\left(R^{2}=0.97\right)$.

As shown in Figure 7c, the measured accumulated decreases in water level near the dam site were slightly lower than the calculated values, while the opposite was observed in reaches farther from the dam site. This is because the model proposed in this paper describes the average condition (i.e., the ideal case in which the riverbed is composed of uniform particles), and the effects of difference in riverbed composition between cross-sections were not considered. Owing to the inherent thinning of riverbed materials along the channel in natural rivers, the relatively coarse riverbed materials near the dam site contributed to the production of a stable sediment layer, which protected the riverbed from continuous erosion resulting from the different sediment transport properties of different particle sizes in heterogeneous riverbeds. In short, the natural distribution of riverbed materials is the fundamental reason for the differences between the measured and the calculated results. Consequently, the coarsening riverbed materials during the erosion process explain the exponential attenuation in channel adjustments, while the continuous thinning of the initial riverbed composition results in the differences between the measured and calculated results where the calculated values are relatively larger in the upper reaches but smaller in the lower reaches (Figure 7c).
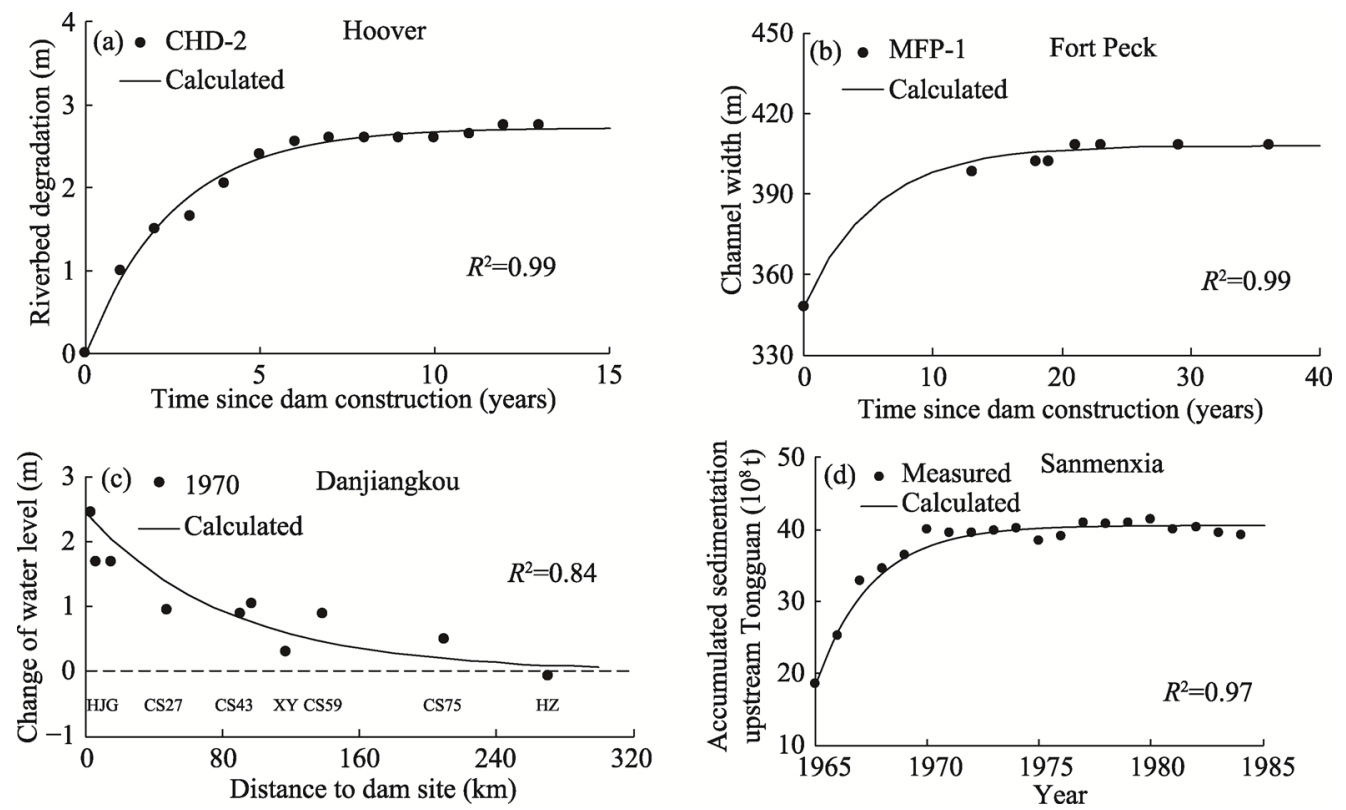

Figure 7 Changes in characteristic river variables following dam construction 


\section{Discussion}

The proposed theoretical models derived from the accumulation phenomena in fluvial processes are generally consistent with the widely used delayed response model in terms of their form. The delayed response model assumes that the adjustment rate of a river morphological variable is proportional to the difference between its value at any time and the asymptotic value. By taking the adjusted result at each time step as the initial condition of the next time step, the cumulative effects of early water and sediment conditions on later riverbed adjustments were considered. Also, the delayed response models were successfully applied to simulate sedimentation in the Sanmenxia Reservoir and the adjustments of channel bankfull morphological dimensions in the lower reaches of the Yellow River over time (Wang et al., 2007; Wu, 2008; Wu et al., 2012). However, based on the delayed response model, it is difficult to reveal the physical mechanisms of accumulation phenomena in fluvial processes. In this study, based on stochastic theory, a mathematical description of the accumulation processes of internal responses induced by external disturbances was derived. By introducing the spatial propagation velocity $v=d x / d t$, theoretical model describing the spatial adjustments of characteristic river variables along the channel was also established. These models provide a new method for simulating of the spatiotemporal adjustments of non-equilibrium fluvial channels following external disturbances.

In the proposed theoretical models, the unknown temporal attenuation coefficient $\alpha$ and the spatial attenuation coefficient $\alpha / v$ are the most crucial parameters directly determining the relative adjustment rates of channel morphological variables. Figure 8 illustrates the relationships between $\alpha, \alpha / v$ and the corresponding dimensionless quantity $1-Q_{\text {post }} / Q_{\text {pre }}$, which represents the relative variation in the average annual peak discharge entering the lower reaches before $\left(Q_{\text {pre }}\right)$ and after $\left(Q_{\text {post }}\right)$ the dam construction. Figure 8 indicates that $\alpha, \alpha / v$ and $1-Q_{\text {post }} / Q_{\text {pre }}$ are positively correlated, with $R$ of 0.80 and 0.61 . That is, the more that the average annual peak discharges are altered, the faster the characteristic channel variables adjust spatially and temporally. Meanwhile, other undetermined model parameters in the developed theoretical models may also be closely related to the flow and sediment regimes in the studied cross-sections and channel reaches. In the future, the theoretical models could be improved by considering the channel flow and sediment conditions, riverbed composition, and erosion resistance (i.e., by developing empirical relationships between riverbed proper-
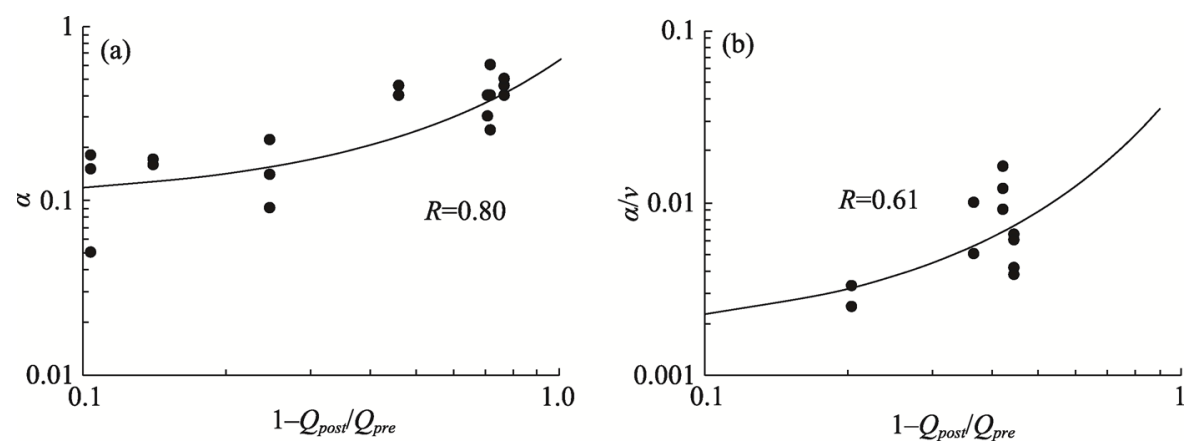

Figure 8 Relationships between $\alpha, \alpha / v$ and relative variation in peak discharge before and after dam construction $\left(1-Q_{\text {post }} / Q_{\text {pre }}\right)$ 
ties and model parameters). This would allow the model to better predict the spatiotemporal readjustments of non-equilibrium fluvial channels after sudden disturbances.

\section{Conclusions}

In this study, the spatiotemporal adjustments of river morphological variables following disturbances were analyzed, and corresponding theoretical models were proposed to describe the accumulation characteristics in fluvial processes. The key conclusions are summarized as follows:

(1) Temporally, the readjustment rates of channel variables following disturbances generally decreased nonlinearly over time. Riverbed degradation, channel width, and accumulated sedimentation increased continuously after dam construction until a new dynamic equilibrium was reached. This phenomenon reflects the accumulation characteristics of fluvial processes. Spatially, the erosion intensity downstream from the dam decreased nonlinearly along the channel until completely diminishing far from the dam. The imbalanced spatial distribution of erosion intensity results from a system response characterized by propagation in space but decay over time.

(2) Assuming that the probability of the external disturbance conforms to a Poisson distribution, and that the response intensity induced by an individual disturbance decays exponentially over time, a mathematical equation describing the temporal accumulation of system responses resulting from external disturbances was proposed. Moreover, the corresponding theoretical models for simulating the spatiotemporal readjustments of characteristic river variables were developed.

(3) The spatiotemporal readjustments of channel morphological variables in the upstream and downstream reaches of dams were simulated using the proposed models. The spatiotemporal readjustments of rivers were accurately described by the developed unified theoretical formula. The model predictions showed good agreements with observed field data with $R^{2}=0.92,0.93,0.76$, and 0.95 for vertical, lateral, longitudinal, and overall readjustment, respectively. In general, it is essential to consider both the accumulation characteristics of fluvial processes and the spatial propagation of system responses to simulate the spatiotemporal readjustments of characteristic river parameters. These factors are the fundamental drivers of river evolution.

(4) The undetermined temporal attenuation coefficient $\alpha$ and the spatial attenuation coefficient $\alpha / v$ are the most crucial parameters in the proposed theoretical models. These parameters determine the relative adjustment rates of channel morphological variables to some extent and play an essential role in channel evolution. In this paper, $\alpha$ and $\alpha / v$ were considered to be constants, and the effects of channel flow-sediment regimes and riverbed composition were not considered. These effects should be further investigated in the future.

\section{References}

Chen J G, Hu C H, Dong Z D et al., 2006. Change of bankfull and bed-forming discharges in the lower Yellow River. Journal of Sediment Research, (5): 10-16. (in Chinese)

Chien N, Zhou W H, Hong R J, 1961. The characteristics and genesis analysis of the braided stream of the lower Yellow River. Acta Geographica Sinica, 28: 1-27. (in Chinese) 
Chien N, 1985. Changes in river regime after the construction of upstream reservoirs. Earth Surface Processes and Landforms, 10(2): 143-159.

Fu R S, Qi M L, Fang H W et al., 2005. Sediment transport characteristics of Yangtze River in river section from Yichang to Hankou. Journal of Hydraulic Engineering, 36(1): 35-41. (in Chinese)

Gardiner C W, 2009. Stochastic Methods. Vol. 4. Berlin: Springer.

Graf W L, 1977. The rate law in fluvial geomorphology. American Journal of Science, 277(2): 178-191.

Hooke J M, 1995. River channel adjustment to meander cutoffs on the River Bollin and River Dane, Northwest England. Geomorphology, 14(3): 235-253.

Jia R M, 1992. Effect of bed erosion and fall of water at the lower reach of Danjiangkou Reservoir on the waterway. Journal of Waterway and Harbor, (4): 12-22. (in Chinese)

Knighton D, 1998. Fluvial Forms and Processes: A New Perspective. London: Routledge.

Liang Z Y, Yang L F, Feng P L, 2005. Relations of channel geometry to water and sediment rate for the lower Yellow River. Journal of Hydroelectric Engineering, 24(6): 68-71. (in Chinese)

Liu N, 2005. On the control of Tongguan elevation and operation mode of Sanmenxia Reservoir. Journal of Hydraulic Engineering, 36(9): 1019-1028. (in Chinese)

Pang J Z, 2005. Some observations on the management strategy of the lower Yellow River. Yellow River, 27(1): 3-4. (in Chinese)

Peng T, Yan H, Guo J L et al., 2016. Impact of Danjiangkou Reservoir operation on downstream hydrological regime. Yangtze River, 47(6): 22-26. (in Chinese)

Qian N, Zhang R, Zhou Z D, 1987. Riverbed Evolution. Beijing: Science Press. (in Chinese)

Qian Y Y, Wu Z, Zhu C X, 1972. Preliminary analysis on maintaining effective storage capacity of reservoirs on heavy sediment-laden river. In: Compilation of Reservoir Sediment Reports, Communication Meeting about the Sediment Observation and Research Achievements of the Yellow River Reservoir. Zhengzhou: Yellow River Institute of Hydraulic Research, 102-111. (in Chinese)

Rahn P H, 1977. Erosion below main stem dams on the Missouri River. Bulletin of the Association of Engineering Geologists, 14(3): 157-181.

Richard G A, 2001. Quantification and prediction of lateral channel adjustments downstream from Cochiti Dam, Rio Grande, NM [D]. Fort Collins: Colorado State University.

Rinaldi M, 2003. Recent channel adjustments in alluvial rivers of Tuscany, Central Italy. Earth Surface Processes and Landforms: The Journal of the British Geomorphological Research Group, 28(6): 587-608.

Simon A, Thorne C R, 1996. Channel adjustment of an unstable coarse-grained stream: Opposing trends of boundary and critical shear stress, and the applicability of extremal hypotheses. Earth Surface Processes and Landforms, 21(2): 155-180.

Wang G Q, Wu B S, Wang Z Y, 2005. Sedimentation problems and management strategies of Sanmenxia Reservoir, Yellow River, China. Water Resources Research, 41: W09417.

Wang S J, 2003. Channel pattern specialities and the formation of the lower reaches of the Yellow River. Acta Geoscientica Sinica, 24(1): 73-78. (in Chinese)

Wang Z Y, Li C Z, Wang F X, 2004. Effect of Tongguan's elevation on the fluvial process of the lower Weihe River. Journal of Hydraulic Engineering, 35(9): 1-8. (in Chinese)

Wang Z Y, Wu B S, Wang G Q, 2007. Fluvial processes and morphological response in the Yellow and Weihe rivers to closure and operation of Sanmenxia Dam. Geomorphology, 91(1/2): 65-79.

Williams G P, Wolman M G, 1984. Downstream effects of dams on alluvial rivers. United States Geological Survey Professional Paper 1286. Washington D. C.: U.S. Government Printing Office, 66-83.

Wu B S, 2008. Delayed response model for fluvial processes of alluvial rivers: II. Model applications. Journal of Sediment Research, (6): 30-37. (in Chinese)

Wu B S, Wang G Q, Xia J Q et al., 2008. Response of bankfull discharge to discharge and sediment load in the Lower Yellow River. Geomorphology, 100(3): 366-376.

Wu B S, Xia J Q, Fu X D et al., 2008. Effect of altered flow regime on bankfull area of the Lower Yellow River, 
China. Earth Surface Processes and Landforms, 33(10): 1585-1601.

Wu B S, Zheng S, Thorne C R, 2012. A general framework for using the rate law to simulate morphological response to disturbance in the fluvial system. Progress in Physical Geography, 36(5): 575-597.

Xia J Q, Li X J, Li T et al., 2014. Response of reach-scale bankfull channel geometry to the altered flow and sediment regime in the lower Yellow River. Geomorphology, 213(4): 255-265.

Xia J Q, Zong Q L, Zhang Y et al., 2014. Prediction of recent bank retreat processes at typical sections in the Jingjiang Reach. Science China Technological Sciences, 57(8): 1490-1499.

Xie J H, 2013. River Evolution and Renovation. Wuhan: Wuhan University Press. (in Chinese)

Xu J X, Zhang O Y, 2000. Complicated fill-scour behaviors of the Huanghe River and the channel-forming processes. Acta Geographica Sinica, 67(3): 274-280. (in Chinese)

Yang Y P, Zhang M J, Sun Z H et al., 2017. The relationship between water level change and river channel geometry adjustment in the downstream of the Three Gorges Dam (TGD). Acta Geographica Sinica, 72(5): 776-789. (in Chinese)

Zhang H W, Huang Y J, Zhao L J et al., 2002. Mathematical model of river bed change downstream of Xiaolangdi Reservoir in early operation period. Journal of Hydroelectric Engineering, 1: 139-145. (in Chinese)

Zhang H W, Liu H L, Jiang E H et al., 1998. Study of evolution trend of wandering channel in the lower Yellow River during sediment storage period of Xiaolangdi Reservoir. Yellow River, 20(11): 5-7. (in Chinese)

Zhang H W, Zhang Q, Jiang E H, 1994. Calculation of dominated discharge in the lower Yellow River. Journal of Sediment Research, (4): 50-55. (in Chinese)

Zhang H W, Zhao L J, Cao F S, 1996. Research of the cause of formation of wandering river model and its changes. Yellow River, 18(10): 11-15. (in Chinese)

Zhao Y A, Pan X D, Fan Z Y et al., 1989. The basic law of souring and filling in the lower Yellow River: Li Baoru (ed.). Collected Scientific Research Papers (Sediment \& Soil and Water Conservation). Zhengzhou: Henan Science and Technology Press, 13-15. (in Chinese) 